\title{
A Neural Mobilization Treatment Strategy for Patients with Neurogenic Claudication Related to Degenerative Lumbar Spinal Stenosis: A Prospective Case Series
}

\author{
Reid Gehring, PT, ScD ${ }^{1}$, Joan Potter-Brunet, PT, DPT , Phillip Sizer, PT, PhD², Kerry Gilbert, PT, ScD \\ and Jean-Michel Brismée, PT, ScD ${ }^{2}$ \\ ${ }^{1}$ Department of Rehabilitation Sciences, Texas Tech University Health Sciences Center, USA \\ ${ }^{2}$ Center for Rehabilitation Research, Texas Tech University Health Sciences Center, USA

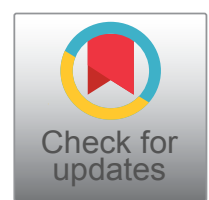

*Corresponding author: Reid Gehring, PT, ScD, Department of Rehabilitation Sciences, Texas Tech University Health Sciences Center, 1400 S. Coulter \#4907, Amarillo, TX 79106, USA

\begin{abstract}
Purpose: To examine the effects of a standardized neural mobilization treatment strategy in patients with Neurogenic Claudication (NC) related to degenerative Lumbar Spinal Stenosis (LSS).

Methods: Prospective case series. Seven older adults with NC related to LSS received a standardized treatment program. Outcome measures included the Swiss Spinal Stenosis questionnaire (SSS), Numeric Pain Rating Scale (NPRS), time to First Symptoms (TFS) and Total Ambulation Time (TAT). Outcomes were assessed at the $7^{\text {th }}$ visit and 3-months.

Results: Improvements were noted at the $7^{\text {th }}$ visit in the NPRS $(p=0.027)$, SSS symptom $(p=0.018)$ and function ( $p$ $=0.017)$, TFS $(p=0.018)$ and TAT $(p=0.027)$. At 3-months, improvements were found in the SSS symptom $(p=0.022)$ and function $(p=0.016)$, but not NPRS $(p=0.115)$. At the $7^{\text {th }}$ visit MCID was met in 5 of 7 participants for the NPRS and SSS symptoms and 7 of 7 for the SSS function. At 3-months the MCID was met in 3 of 5 participants in the NPRS, 4 of 5 in SSS symptoms, and 5 of 5 in SSS function.

Conclusion: Clinically meaningful improvements in pain and functional outcome measures were noted after the application of a standardized neural mobilization treatment strategy both immediately after the treatment period and at 3 month follow-up.
\end{abstract}

\section{Keywords}

Neural mobilization, Neurogenic claudication, Walking tolerance, Hip mobilization, Lumbar spinal stenosis

\begin{abstract}
Abbreviations
HEP: Home Exercise Program; LSS: Lumbar Spinal Stenosis; MRI: Magnetic Resonance Imaging; MCID: Minimally Clinically Important Difference; NC: Neurogenic Claudication; NPRS: Numeric Pain Rating Scale; SSS: Swiss Spinal Stenosis Questionnaire; TFS: Time to First Symptoms; TAT: Total Ambulation Time
\end{abstract}

\section{Introduction}

Degenerative Lumbar Spinal Stenosis (LSS) is a condition most often observed in people over 60-years-old $[1,2]$. It is the most common indication for spinal surgery in people older than 65 years [3] and is associated with three main areas of stenosis due to spinal degeneration: Central canal, lateral recess, and intervertebral foramen [4]. The degeneration leads to diminished space around the neural and vascular elements, which can eventually result in symptoms of lower limb Neurogenic Claudication (NC) [4,5]. Neurogenic claudication is a common complaint in people suffering from degenerative LSS that is characterized by lower limb symptoms during standing and walking activities [3]. Common symptoms include unilateral or bilateral leg pain, fatigue, paresthesia, and/or tightness ultimately resulting in impaired ability to stand or walk for prolonged periods of time $[5,6]$. These symptoms are relieved during sitting and/or in positions of lumbar flexion [4].

Citation: Gehring R, Potter-Brunet J, Sizer P, Gilbert K, Brismée JM (2021) A Neural Mobilization Treatment Strategy for Patients with Neurogenic Claudication Related to Degenerative Lumbar Spinal Stenosis: A Prospective Case Series. Int J Sports Exerc Med 7:191. doi.org/10.23937/2469-5718/1510191 Accepted: May 01, 2021; Published: May 03, 2021

Copyright: (C) 2021 Gehring R, et al. This is an open-access article distributed under the terms of the Creative Commons Attribution License, which permits unrestricted use, distribution, and reproduction in any medium, provided the original author and source are credited. 
These common clinical symptoms are frequently related to spinal canal diameter changes with specific positions and movements. For example, spinal canal diameters increase with sitting and lumbar flexion, while they decrease with lumbar extension and in activities that load the spine such as standing and walking [7-9]. In addition, lumbar extension and walking increase epidural pressure which leads to increased compression of neural and vascular structures within the central spinal canal [10] and in the intervertebral foramen [9].

There is a growing body of evidence supporting conservative multi-modal treatment programs for managing degenerative LSS [11-15]. The design of these multi-modal treatment approaches vary but each often include stretching activities, lumbar strengthening, hip and spine mobilization, mechanical traction, neural mobilization, and aerobic exercise. Treatment duration in these studies also varies between 9-15 treatment sessions over a period of 3-6 weeks. These programs have demonstrated immediate and mid-term benefits, with one study reporting sustained benefit in a majority of subjects at one year [15]. Though the interventions in each study differed, each included an aerobic exercise component involving cycling or body-weight supported treadmill walking. Some authors incorporate aerobic exercises to improve the patients' overall fitness and for leg conditioning [11], while others emphasize that specific spinal positioning during aerobic exercise provides additional benefit by improving neural tissue hemodynamics [14-17].

Neural mobilization exercise is a treatment option for symptomatic LSS and may be a beneficial self-management option for patients with this condition. These exercises, in particular a supine tensioner technique, have been emphasized to varying degrees in studies examining multimodal conservative interventions for LSS $[11,14,18]$. Neural mobilization exercises are thought to facilitate neural gliding, improve tissue vascularity and disperse noxious fluids $[19,20]$. These effects may translate toward improved health and functioning of compressed neural tissue enabling the tissue to meet the metabolic and functional demands needed during walking activities. Neural mobilization exercises can be easily performed by patients at home, require no special equipment, and take little time to perform as a daily maintenance program.

Limitations in hip extension are commonly found in older adults [21], and patients may compensate for this loss of motion with anterior pelvic tilting and lumbar extension during gait $[21,22]$ resulting in a dynamic narrowing of the lumbar spinal canals. Thus, using manual therapy to address hip motion limitations may prove beneficial in patients with LSS. Several studies have incorporated manual therapy to mobilize both the spine and hips to treat patients with symptomatic LSS $[11,15,16,18]$.
The double knee to chest stretch is commonly used as a flexion-based exercise to promote opening of the spinal canals and to stretch tight lumbar paraspinal musculature $[12,23,24]$. This exercise is simple to perform and can be included in a Home Exercise Program (HEP).

The purpose of this study was to observe the effects of a neural mobilization treatment strategy on a group of patients with NC related to LSS.

\section{Methods}

\section{Design}

This study is a prospective case series. Systematic consecutive sampling was used so that all patients screened that met the inclusion/exclusion criteria were asked to participate in the study and were included upon signing informed consent forms. Interventions were performed at a university-based outpatient clinic in Amarillo, Texas. The study protocol was approved by the Institutional Review Board at Texas Tech University Health Sciences Center.

\section{Participants}

Patients were recruited from local physician offices in the panhandle region of Texas from January 2018 July 2019. The referral sources included neurosurgeons, an orthopedic spinal surgeon, and a neurologist. The principal investigator conducted a routine comprehensive physical therapy examination to determine the patient's clinical status. An additional investigator recorded the outcome measures. Seven participants with a mean age of $68.6 \pm 8.8$ years with reports of NC related to LSS were included in this study.

\section{Inclusion criteria}

The inclusion criteria were participants aged 50-89 years-old, clinical symptoms of intermittent unilateral or bilateral leg pain occurring with walking and standing activities relieved only with sitting or by assuming flexed positions, leg symptoms rated as greater than $4 / 10$ on the Numeric Pain Rating Scale (NPRS) and provoked within 15 minutes of walking, and Magnetic Resonance Imaging (MRI) confirmed lumbar spinal stenosis.

\section{Exclusion criteria}

The exclusion criteria were previous lumbar surgery that included fusion, spinal injection in the last 6 weeks, impaired walking tolerance due to factors other than neurogenic claudication, inability to follow the rater's instructions, medical contraindication for hip mobilizations in extension or flexion, or any current medico-legal issues.

\section{Intervention}

The participants attended 7 physical therapy visits ( 6 for treatment, 1 for outcome assessment), and were 
treated 2 times per week for 3 weeks. Participants were asked to not alter their medication intake during the entire study period. The intervention was performed by the primary investigator who is a licensed physical therapist with 11 years of clinical experience and is a board-certified clinical specialist in orthopaedic physical therapy.

\section{Double knee to chest stretches}

The participant laid supine on a treatment table. The participant drew both knees as close to their chest as possible using their hands. This was repeated 3 times for 60 seconds (Figure 1a).

\section{Hip extension mobilizations}

The participant was placed in sidelying. The table side hip and knee were flexed to approximately 90 degrees. A mobilization strap was placed around their pelvis and secured to the treatment table to stabilize the pelvis. The clinician grasped the participant's top leg placing the palm behind the greater trochanter and the other hand under the participant's knee keeping it in a

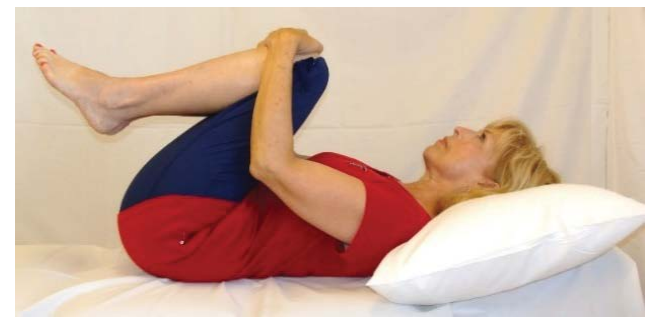

(a)

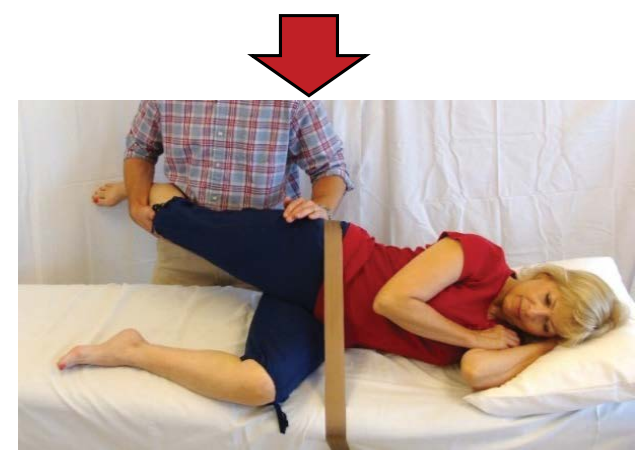

(b)

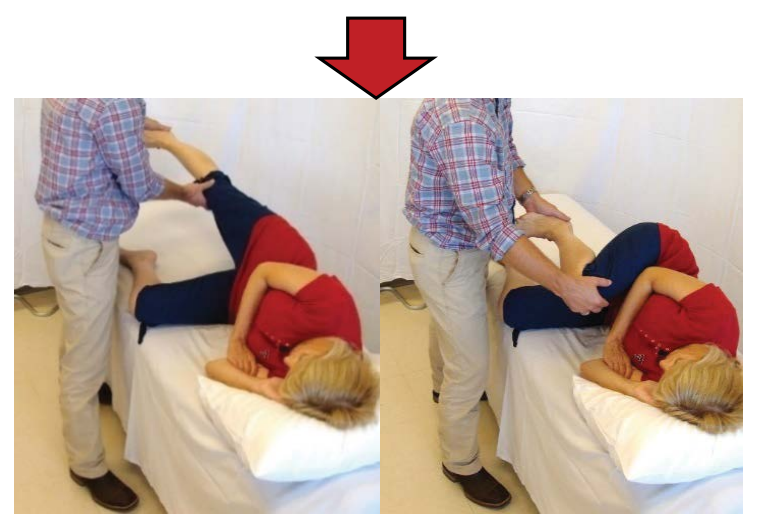

(c)

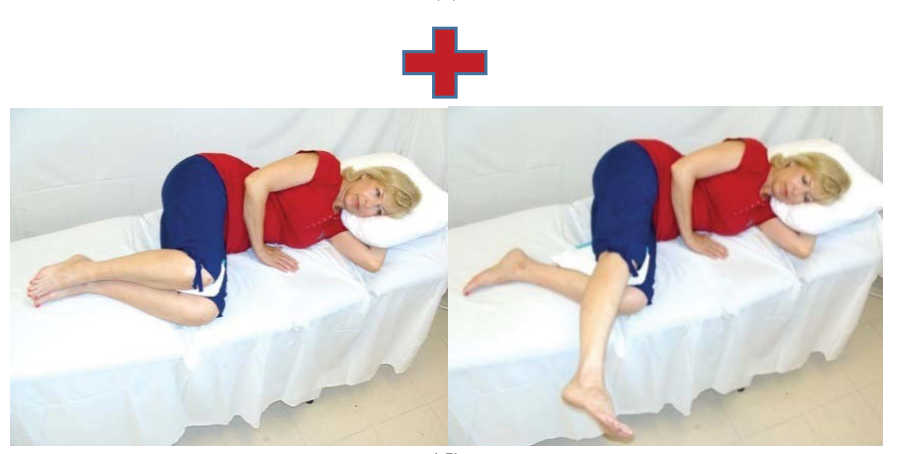

(d)

Figure 1: (a) Double knee to chest stretch; (b) Sidelying hip extension mobilization; (c) Passive neural mobilization; (d) Active neural mobilization 
slightly flexed position. The clinician moved the participant's hip into extension until a barrier was felt and then performed 2 sets of 30 grade III or IV oscillations in a dorsal-to-ventral direction. This was performed on each hip (Figure 1b).

\section{Passive side lying neural mobilization}

The participant was placed in side lying. Their trunk was partially flexed forward to promote opening of the lumbar neural canals. The table side hip and knee were flexed to approximately 90 degrees. The clinician grasped the participant's top knee with one hand and their heel with the other. The clinician passively moved the participant's lower extremity into full hip and knee flexion then into neutral hip extension and full knee extension $[25,26]$. This process was repeated for a total of 5 sets of 30 repetitions at one cycle every 2 seconds on each lower extremity (Figure 1c).

\section{Home exercise program}

This consisted of double knee to chest stretches (3 $\times 60$ seconds) and active sidelying neural mobilization exercises. The participant flexed their trunk slightly forward, flexed their hips to approximately 80 degrees and their knees to approximately 90 degrees. The participant then actively moved their knee into extension then returned to the starting position. This was repeated for 30 repetitions on each side (Figure $1 \mathrm{~d}$ ). Participants were asked to perform the HEP twice daily during the treatment period and for at least 3 months after discharge.

\section{Outcome measures}

Swiss Spinal Stenosis questionnaire (SSS): The SSS is a condition specific measure for patients with lumbar spinal stenosis. It consists of three separate subscales: Symptom severity, functional, and satisfaction. Lower scores represent fewer symptoms, greater function, and greater satisfaction with the results of treatment. The Minimal Clinically Important Difference (MCID) for the SSS symptom subscale is 0.36 and the functional subscale is 0.10 [27]. We substituted the word "surgery" in the satisfaction subscale and replaced it with "physical therapy treatment" in order to reflect the type of intervention the participant received.

Numerical Pain Rating Scale (NPRS): The NPRS has good test-retest reliability (ICC $=0.61)$ [28]. This measure uses an 11 point scale where " 0 " represents "no pain" and "10" represents "the worst imaginable pain". The MCID for NPRS in the LSS population is 1.5 [27]. Participants were asked to rate their average pain with walking activities during the past week.

Time to First Symptoms (TFS): Time to first symptoms assesses the amount of time it takes for leg symptom onset during ambulation. This measure has goodtest-retest reliability $(C C C=0.98)$ in subjects with lumbar spinal stenosis [29]. Participants walked on a treadmill in a fully erect posture at a self-selected comfortable pace and reported the first moment of leg symptom onset. Maximal walking time permitted was 15 minutes [29].

Total Ambulation Time (TAT): Total ambulation time is an objective test to measure walking tolerance and has good test-retest reliability $(C C C=0.96)$ in subjects with lumbar spinal stenosis [29]. Participants walked at a self-selected comfortable pace until they experienced symptom reproduction at a level that would cause them to stop walking in usual daily life situations [29]. Maximal walking time permitted was 15 minutes.

A secondary investigator, who did not provide patient treatment, assessed all outcome measures and was blinded to the baseline outcome measure scores during outcome reassessment. All outcome measures and HEP compliance were assessed at the initial examination and at the $7^{\text {th }}$ visit. The NPRS, SSS subscales and HEP compliance were reassessed at 3-month follow-up using questionnaires mailed to the participants. Participants in this study received all physical therapy visits free of charge.

\section{Statistical analyses}

Descriptive statistics were used to assess the following outcome measures: (1) SSS symptom and functional subscales (baseline, $7^{\text {th }}$ visit, 3-month follow-up) and SSS satisfaction subscale ( $7^{\text {th }}$ visit, 3-month follow-up); (2) NPRS (baseline, $7^{\text {th }}$ visit and 3-month follow-up); (3) TFS and TAT (baseline and $7^{\text {th }}$ visit).

Statistical analyses were performed using SPSS version 25.0 (IBM Corp.). Data did not meet the assumptions of parametric data, therefore non-parametric tests were used. Statistical tests were performed as twotailed tests with a significance level of 0.05 .

Group differences between baseline and $7^{\text {th }}$ visit for the NPRS, SSS symptom and functional subscales were assessed using Wilcoxon signed-ranks test. Effect size was determined using: $r=Z / V N$. Group differences between three time intervals (baseline, $7^{\text {th }}$ visit, and 3-month follow-up) were assessed using the Friedman 2-way ANOVA by ranks. Effect size was determined using Kendall's W.

The Wilcoxon signed-ranks test was used to assess group differences for TFS and TAT (time: baseline vs. $7^{\text {th }}$ visit). Effect size was determined using: $r=Z / V N$.

\section{Results}

A total of 10 patients were recruited and screened for study participation; eight met the inclusion/exclusion criteria and consented to participate. One participant attended three treatment sessions, but withdrew from the study due to his inability to attend the planned follow-up visits. Data from seven participants were used for data analysis. Clinical examination and MRI findings for each participant are provided in (Table 1). All seven participants were reassessed at the $7^{\text {th }}$ visit. Five of the 
Table 1: Clinical and MRI examination findings.

\begin{tabular}{|c|c|c|c|c|c|c|c|}
\hline Participant & Age & $\begin{array}{l}\text { Laterality of } \\
\text { symptoms }\end{array}$ & $\begin{array}{l}\text { SLR } \\
\text { results }\end{array}$ & $\begin{array}{l}\text { Symptom } \\
\text { duration } \\
\text { (months) }\end{array}$ & $\begin{array}{l}\text { Spondylo. } \\
\text { (MRI) }\end{array}$ & $\begin{array}{l}\text { Central canal } \\
\text { stenosis (MRI) }\end{array}$ & $\begin{array}{l}\text { Lateral foraminal } \\
\text { stenosis (MRI) }\end{array}$ \\
\hline 1 & 71 & Right & Neg. & 4 & None & Sev L4-5 & $\begin{array}{l}\text { Mild B L3-4 } \\
\text { Sev B L4-5 } \\
\text { Mod B L5-1 }\end{array}$ \\
\hline 2 & 75 & Right & $\begin{array}{l}\text { Pos. } \\
(R)\end{array}$ & 6 & $\begin{array}{l}\text { L4-5 } \\
\text { (Grade 1) }\end{array}$ & Mild L3-4 & $\begin{array}{l}\text { Mild L L3-4 } \\
\text { Mild B L4-5 }\end{array}$ \\
\hline 3 & 79 & Bilateral & $\begin{array}{l}\text { Pos. } \\
\text { (B) }\end{array}$ & 4 & $\begin{array}{l}\text { L4-5 } \\
\text { (Grade 1) }\end{array}$ & $\begin{array}{l}\text { Mild L3-4 } \\
\text { Sev L4-5 }\end{array}$ & $\begin{array}{l}\text { Sev B L4-5 } \\
\text { Sev B L5-1 }\end{array}$ \\
\hline 4 & 65 & Bilateral & $\begin{array}{l}\text { Pos. } \\
\text { (L) }\end{array}$ & $\approx 24$ & $\begin{array}{l}\text { L4-5 } \\
\text { (Grade 1) }\end{array}$ & $\begin{array}{l}\text { Mild L1-2 } \\
\text { Mild L3-4 } \\
\text { Sev L4-5 }\end{array}$ & $\begin{array}{l}\text { Mild B L2-3 } \\
\text { Mod B L3-4 } \\
\text { Sev B L4-5 } \\
\text { Sev L L5-1 }\end{array}$ \\
\hline 5 & 72 & Bilateral & Neg. & $\approx 24$ & $\begin{array}{l}\text { L5-1 } \\
\text { (Grade 1) }\end{array}$ & $\begin{array}{l}\text { Mild L2-3 } \\
\text { Mild L3-4 } \\
\text { Mod L4-5 }\end{array}$ & $\begin{array}{l}\text { Mild B L3-4 } \\
\text { Mild R L4-5 }\end{array}$ \\
\hline 6 & 66 & Bilateral & Neg. & 7 & $\begin{array}{l}\text { L5-1 } \\
\text { (Grade 1) }\end{array}$ & $\begin{array}{l}\text { Sev L2-3 } \\
\text { Mild L3-4 } \\
\text { Mild L4-5 } \\
\text { Mild L5-1 }\end{array}$ & $\begin{array}{l}\text { Sev B L2-3 } \\
\text { Mod R L3-4 } \\
\text { Mild L L3-4 } \\
\text { Sev B L5-1 }\end{array}$ \\
\hline 7 & 52 & Right & Neg. & $\approx 24$ & $\begin{array}{l}\text { L4-5 } \\
\text { (Grade 1) }\end{array}$ & $\begin{array}{l}\text { Mod L4-5 } \\
\text { Sev L5-1 }\end{array}$ & Mild L L4-5 \\
\hline
\end{tabular}

Abbreviations: B: Bilateral; L: Left; R: Right; Mod: Moderate; Neg: Negative; Pos: Positive; Sev: Severe; SLR: Straight leg raise: Spondylo: Spondylolisthesis

Table 2: Numerical pain rating scale.

\begin{tabular}{|l|l|l|l|}
\hline Participant & Baseline & $\mathbf{7}^{\text {th }}$ Visit & 3-month \\
\cline { 2 - 4 } & NPRS & NPRS & NPRS \\
\hline 1 & 5 & $2^{\mathrm{a}}$ & $\mathrm{n} / \mathrm{a}$ \\
\hline 2 & 6 & $1^{\mathrm{a}}$ & $1^{\mathrm{a}}$ \\
\hline 3 & 5 & 5 & $\mathrm{n} / \mathrm{a}$ \\
\hline 4 & 7 & $2^{\mathrm{a}}$ & $1^{\mathrm{a}}$ \\
\hline 5 & 5.5 & $4^{\mathrm{a}}$ & 6 \\
\hline 6 & 6 & 5 & 6 \\
\hline 7 & 7 & $3^{\mathrm{a}}$ & $2^{\mathrm{a}}$ \\
\hline Median & 6 & 3 & 2 \\
\hline Change by & group & $\mathrm{p}=0.027^{\mathrm{b}}$ & $\mathrm{p}=0.115$ \\
\hline Effect size & & 0.589 & 0.433 \\
\hline
\end{tabular}

Abbreviations: NPRS, Numerical Pain Rating Scale.

a Values exceeding MCID from baseline; ' Significant difference between group baseline and $7^{\text {th }}$ visit scores $(p<0.05)$

seven participants were reassessed at the 3-month follow-up; two participants elected to have surgery.

\section{Numerical Pain Rating Scale (NPRS)}

Significant NPRS score improvements were found between baseline and the $7^{\text {th }}$ visit $(p=0.027)$, but not at 3 -months $(p=0.115)$. Five of seven participants met the MCID for the NPRS at the $7^{\text {th }}$ visit and 3 of 5 participants met the MCID for the NPRS at 3-months (Table 2).
Table 5: Swiss Spinal Stenosis Questionnaire (satisfaction subscale).

\begin{tabular}{|l|l|l|}
\hline \multirow{2}{*}{ Participant } & $\mathbf{7}^{\text {th }}$ Visit & 3-month \\
\cline { 2 - 3 } & SSS Satisfaction & SSS Satisfaction \\
\hline 1 & 1.92 & $\mathrm{n} / \mathrm{a}$ \\
\hline 2 & 1.00 & 1.00 \\
\hline 3 & 1.50 & $\mathrm{n} / \mathrm{a}$ \\
\hline 4 & 1.00 & 1.00 \\
\hline 5 & 1.50 & 1.30 \\
\hline 6 & 2.17 & 4.00 \\
\hline 7 & 1.00 & 1.17 \\
\hline
\end{tabular}

SSS Satisfaction scale ranges: 1 - Very satisfied, 2 - Somewhat satisfied, 3 - Somewhat dissatisfied, 4 - Very dissatisfied.

\section{Swiss Spinal Stenosis (SSS) symptom subscale}

Significant improvements were found at both the $7^{\text {th }}$ visit $(p=0.018)$ and at 3 -months $(p=0.022)$. Five of seven participants met the MCID at the $7^{\text {th }}$ visit and 4 of 5 met MCID at 3-months (Table 3).

\section{Swiss Spinal Stenosis (SSS) functional subscale}

Significant improvements were found at the $7^{\text {th }}$ visit $(p=0.017)$ and at 3-months $(p=0.016)$. All participants met the MCID at the $7^{\text {th }}$ visit and 5 of 5 reported the MCID at 3-months (Table 3). 
Table 3: Swiss Spinal Stenosis Questionnaire (symptom and functional).

\begin{tabular}{|c|c|c|c|c|c|c|}
\hline \multirow{2}{*}{ Participant } & \multicolumn{2}{|l|}{ Baseline } & \multicolumn{2}{|l|}{$7^{\text {th }}$ Visit } & \multicolumn{2}{|l|}{ 3-month } \\
\hline & SSS symptom & SSS function & SSS symptom & SSS function & SSS symptom & SSS function \\
\hline 1 & 3.14 & 2.4 & 3 & $2^{\mathrm{a}}$ & $\mathrm{n} / \mathrm{a}$ & $\mathrm{n} / \mathrm{a}$ \\
\hline 2 & 3.5 & 1.8 & $1.43^{a}$ & $1^{a}$ & $1.29^{a}$ & $1^{a}$ \\
\hline 3 & 3.64 & 2.2 & $2.71^{a}$ & $1.8^{\mathrm{a}}$ & $\mathrm{n} / \mathrm{a}$ & n/a \\
\hline 4 & 3 & 2.4 & $1.43^{\mathrm{a}}$ & $1.6^{\mathrm{a}}$ & $1.71^{a}$ & $1.4^{\mathrm{a}}$ \\
\hline 5 & 3.71 & 2.8 & $2.43^{a}$ & $1.6^{\mathrm{a}}$ & $3^{a}$ & $1.8^{\mathrm{a}}$ \\
\hline 6 & 3.29 & 3.4 & 3.14 & $3.2^{\mathrm{a}}$ & 3 & $3^{a}$ \\
\hline 7 & 3 & 2.4 & $1.71^{\mathrm{a}}$ & $2.2^{\mathrm{a}}$ & $1.28^{a}$ & $1.2^{\mathrm{a}}$ \\
\hline Median & 3.29 & 2.4 & 2.43 & 1.8 & 1.71 & 1.4 \\
\hline \multicolumn{3}{|c|}{ Change by group } & $p=0.018^{b}$ & $p=0.017^{b}$ & $p=0.022^{c}$ & $p=0.016^{c}$ \\
\hline \multicolumn{3}{|l|}{ Effect size } & 0.632 & 0.635 & 0.760 & 0.832 \\
\hline
\end{tabular}

Abbreviations: SSS, Swiss Spinal Stenosis Questionnaire.

aValues exceeding MCID from baseline; ' Significant difference between group baseline and $7^{\text {th }}$ visit scores $(p<0.05)$; ${ }^{c}$ Significant difference between group baseline, $7^{\text {th }}$ visit, 3-month scores $(p<0.05)$.

Table 4: Walking measures.

\begin{tabular}{|c|c|c|c|c|}
\hline \multirow{2}{*}{ Participant } & \multicolumn{2}{|l|}{ Baseline } & \multicolumn{2}{|l|}{$7^{\text {th }}$ Visit } \\
\hline & TFS (seconds) & TAT (seconds) & TFS (seconds) & TAT (seconds) \\
\hline 1 & 39 & 184 & 152 & 232 \\
\hline 2 & 120 & 471 & $900^{a}$ & $900^{\mathrm{a}}$ \\
\hline 3 & 99 & 362 & 147 & $900^{a}$ \\
\hline 4 & 151 & 166 & 212 & 212 \\
\hline 5 & 50 & 243 & 246 & 672 \\
\hline 6 & 51 & 142 & 114 & 291 \\
\hline 7 & 33 & $900^{a}$ & 389 & $900^{a}$ \\
\hline Median & 51 & 243 & 212 & 672 \\
\hline \multicolumn{3}{|c|}{ Change by group } & $p=0.018^{b}$ & $p=0.027^{b}$ \\
\hline \multicolumn{3}{|l|}{ Effect size } & 0.632 & 0.589 \\
\hline
\end{tabular}

Abbreviations: TFS, Time to First Symptoms; TAT, Total Ambulation Time.

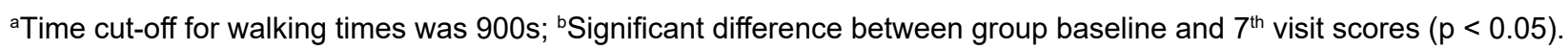

Time to First Symptoms (TFS) and Total Ambulation Time (TAT)

Walking times improved in all participants (Table 4). Significant changes in walking times were found at the $7^{\text {th }}$ visit in the TFS $(p=0.018)$ and TAT $(p=0.027)$. Additionally, we noted that self-selected comfortable walking speeds increased in 6 of 7 participants and group median walking speeds increased from $1.2 \mathrm{mph}$ (range $0.9-3.0$ ) to $1.5 \mathrm{mph}$ (range $1.0-3.2$ ) at the $7^{\text {th }}$ visit. Walking distances for TFS improved from a median of $88 \mathrm{ft}$ to $578 \mathrm{ft}$ and group distances for TAT improved from a median of $428 \mathrm{ft}$ to $1579 \mathrm{ft}$.

\section{Discussion}

This is the first study to report outcomes of a standardized neural mobilization treatment program in people diagnosed with MRI confirmed degenerative LSS.

Clinically meaningful improvements in pain and func- tional outcome measures were noted immediately after the treatment period and at mid-term follow-up. The study participants reported high satisfaction rates with the treatment and benefits received; these high satisfaction rates were noted at the $7^{\text {th }}$ visit and at 3-months (Table 5).

Participants who demonstrated the best response to this treatment regimen tended to display higher baseline NPRS, less lateral foraminal degeneration on MRI, less combined lateral foraminal and central canal stenosis on MRI, and longer symptom duration. Such observations could assist in identifying a subgroup of patients who are most likely to benefit from this treatment regimen; however, larger studies are necessary to confirm these findings.

There is ongoing debate regarding the exact cause of neurogenic claudication. Patients with LSS experience increased pressures in the epidural and intraforaminal 
spaces during standing and walking $[9,10]$. It is thought that increased epidural and intraforaminal pressures may result in neural ischemia, venous flow interruption with subsequent venous engorgement, or a combination of both $[30,31]$. The improvements in participant symptoms and walking tolerance in this study may have resulted from improvements in the overall health and fluid dynamics of the chronically compressed neural structures.

The purported benefits of neural mobilization are numerous and include facilitating nerve gliding, reducing nerve adherence, dispersion of noxious fluids, increasing neural vascularity, improving axoplasmic flow, and reducing dorsal horn and supraspinal sensitization $[19,32]$. Prior research demonstrated that both specific movements and general lower extremity range of motion resulted in sciatic nerve excursion $[32,33]$.

Furthermore, neural mobilization exercises in the lower limb have been shown to alter neural fluid dynamics as far proximal as the L4 dural space [20]. Hip extension mobilizations are thought to improve hip extensibility during gait thereby reducing further increases in epidural and intraforaminal pressures that occur with compensatory lumbar extension and subsequent narrowing of the neural canals. Double knee to chest stretches may improve fluid dynamics in the affected neural structures by temporarily reducing neural compression in the central and lateral vertebral canals [9] and lengthening lumbar extensor musculature.

The positive results found in participants that completed the 3-month follow-up indicate that a HEP including neural mobilization and double knee to chest stretches may be beneficial for symptom maintenance. Study participants reported a high HEP compliance rate of $100 \%$ at the $7^{\text {th }}$ visit and $75 \%$ at 3-month follow-up.

Two participants were unavailable at the 3-month follow-up due to electing for surgery. The outcome measures at the $7^{\text {th }}$ visit showed that one of these participantsmet the MCID in the NPRS and SSS symptom subscale, but had minimal improvements in walking measures. The other participantmet the MCID in the SSS symptom and functional subscales, demonstrated a small increase in TFS, and demonstrated a dramatic improvement in TAT. Compared to other participants, these two participants expressed an interest in receiving surgery for their condition prior to inclusion in the study.

Study limitations include the small sample size and lack of a control group. These two factors limit the ability to assess whether a true treatment effect occurred in response to study interventions. Additionally, the long-term treatment effects were not assessed as the follow-up time was limited to three months.

\section{Conclusion}

This study describes a neural mobilization treatment strategy for patients with NC related to LSS. Neural mobilization, in particular the slider technique, is an often overlooked treatment approach for this patient population. Significant and clinically meaningful improvements were observed in pain symptoms, self-report functional mobility, and walking tolerance. Clinicians are encouraged to consider incorporating this neural mobilization strategy in their treatment approach for this patient population.

\section{Authors Declarations}

The authors report no conflicts of interest.

All authors provided a substantial contribution to the design and review of this study.

\section{References}

1. Konno S, Kikuchi S, Tanaka Y, Yamazaki K, Shimada Y, et al. (2007) A diagnostic support tool for lumbar spinal stenosis: a self-administered, self-reported history questionnaire. BMC Musculoskelet Disord 8: 102.

2. Sugioka T, Hayashino $Y$, Konno S, Kikuchi S, Fukuhara $S$ (2008) Predictive value of self-reported patient information for the identification of lumbar spinal stenosis. Fam Pract 25: 237-244.

3. Lurie J, Tomkins-Lane C (2016) Management of lumbar spinal stenosis. BMJ (Clinical research ed.) 352: h6234

4. Genevay S, Atlas S (2010) Lumbar Spinal Stenosis. Best Practice and Research Clinical Rheumatology 24: 253-265.

5. Kreiner DS, Shaffer WO, Baisden JL, Gilbert TJ, Summers JT, et al. (2013) An evidence-based clinical guideline for the diagnosis and treatment of degenerative lumbar spinal stenosis (update). Spine J 13: 734-743.

6. Tompkins-Lane C, Holz S, Yamakawa K, Phalke VV, Quint DJ, et al. (2012) Predictors of walking performance and walking capacity in people with lumbar spinal stenosis, low back pain, and asymptomatic controls. ArchPhys MedRehabil 93: 647-653.

7. Inufusa A, An H, Lim TH, Hasegawa T, Haughton VM, et al. (1996) Anatomic changes of the spinal canal and intervertebral foramen associated with flexion-extension movement. Spine 21: 2412-2420.

8. Kanno H, Ozawa H, Koizumi Y, Morozumi N, Aizawa T, et al. (2012) Dynamic change of dural sac cross-sectional area in axial loaded magnetic resonance imaging correlates with the severity of clinical symptoms in patients with lumbar spinal canal stenosis. AJNR Am J Neuroradiol 33: 1191-1197.

9. Morishita Y, Hida S, Naito M, Arimizu J, Takamori Y (2009) Neurogenic intermittent claudication in lumbar spinal canal stenosis: the clinical relationship between the local pressure of the intervertebral foramen and the clinical findings in lumbar spinal canal stenosis. J Spinal Disord Tech 22: 130-134.

10. Takahashi K, Kagechika K, Takino T, Matsui T, Miyazaki T, et al. (1995) Changes in epidural pressure during walking in patients with lumbar spinal stenosis. Spine 20: 2746-2749.

11. Ammendolia C, Chow N (2015) Clinical outcomes for neurogenic claudication using a multimodal program for lumbar spinal stenosis: a retrospective study. J Manipulative Physiol Ther 38: 188-194.

12. Goren A, Yildiz N, Topuz O, Findikoglu G, Ardic F (2010) 
Efficacy of exercise and ultrasound in patients with lumbar spinal stenosis: a prospective randomized controlled trial. Clin Rehabil 24: 623-631.

13. Minetama M, Kawakami M, Teraguchi M, Kagotani R, Mera $Y$, et al. (2019) Supervised physical therapy vs. home exercise for patients with lumbar spinal stenosis: a randomized controlled trial. Spine J 19: 1310-1318.

14. Pua Y, Cai C, Lim K (2007) Treadmill walking with body weight support is no more effective than cycling when added to an exercise program for lumbar spinal stenosis: a randomised controlled trial. Aust J Physiother 53: 83-89.

15. Whitman JM, Flynn TW, Childs JD, Wainner R, Gill Howard, et al. (2006) A comparison between two physical therapy treatment programs for patients with lumbar spinal stenosis. Spine 31: 2541-2549.

16. Backstrom KM, Whitman J, Flynn TW (2011) Lumbar spinal stenosis: diagnosis and management of the aging spine. Man Ther 16: 308-317.

17. Whitman JM, Flynn TW, Fritz JM (2003) Nonsurgical management of patients with lumbar spinal stenosis: A literature review and a case series of three patients managed with physical therapy. Phys Med Rehabil Clin N Am 4: 77-101.

18. Murphy DR, Hurwitz EL, Gregory AA, Clary R (2006) A non-surgical approach to the management of lumbar spinal stenosis: a prospective observational cohort study. BMC Musculoskelet Disord 7: 16.

19. Ellis RF, Hing WA (2008) Neural mobilization: a systematic review of randomized controlled trials with an analysis of therapeutic efficacy. J Man Manip Ther 16: 8-22.

20. Gilbert KK, Smith MP, Sobczak S, James CR, Sizer PS, et al. (2015) Effects of lower limb neurodynamic mobilization on intraneural fluid dispersion of the fourth lumbar nerve root: an unembalmed cadaveric investigation. J Man Manip Ther 23: 239-245.

21. Lee LW, Zavarei K, Evans J, Lelas JJ, Riley PO, et al. (2005) Reduced Hip Extension in the Elderly: Dynamic or Postural? Arch Phys Med Rehabil 86: 1851-1854.

22. Kerrigan DC, Xenopoulos-Oddsson A, Sullivan MJ, Lelas JJ, Riley PO (2003) Effect of a hip flexor stretching program on gait in the elderly. Arch Phys Med Rehabil 84: 1-6.
23. Bodack M, Monteiro ME (2001) Therapeutic exercise in the treatment of patients with lumbar spinal stenosis. Clin Orthop Relat Res 384: 144-152.

24. Fritz JM, Delitto A, Welch WC, Erhard RE (1998) Lumbar spinal stenosis: A review of current concepts in evaluation, management, and outcome measurements. Arch Phys Med Rehabil 79: 700-708.

25. Satpute K, Hall T, Bisen R, Lokhande P (2019) The effect of spinal mobilization with leg movement in patients with lumbar radiculopathy - A double blind randomized controlled trial. Arch Phys Med Rehabil 100: 828-836.

26. Schafer A, Hall T, Muller G, Briffa K (2011) Outcomes differ between subgroups of patients with low back and leg pain following neural manual therapy: a prospective cohort study. Eur Spine J 20: 482-490.

27. Cleland J, Whitman J, Houser J, Wainner R, Childs JD (2012) Psychometric properties of selected tests in patients with lumbar spinal stenosis. Spine J 12: 921-931.

28. Childs J, Piva S, Fritz J (2005) Responsiveness of the numeric pain rating scale in patients with low back pain. Spine 30: 1331-1334.

29. Deen HG, Zimmerman RS, Lyons MK, McPhee MC, Verheijde JL, et al. (2000) Test-retest reproducibility of the exercise treadmill examination in lumbar spinal stenosis. Mayo Clin Proc 75: 1002-1007.

30. Kobayashi S, Suzuki Y, Meir A, Al-Kuhdairi N, Nakan T, et al. (2015) Circulatory dynamics of the cauda equina in lumbar canal stenosis using dynamic contrast-enhanced magnetic resonance imaging. Spine J 15: 2132-2141.

31. Porter RW, Ward D (1992) Cauda equina dysfunction: the significance of two-level pathology. Spine 17: 9-15.

32. Ellis RF, Hing WA, McNair PJ (2012) Comparison of longitudinal sciatic nerve movement with different mobilization exercises: an in vivo study utilizing ultrasound imaging. J Orthop Sports Phys Ther 42: 667-675.

33. Coppieters MW, Butler DS (2008) Do sliders slide and tensioners tension? An analysis of neurodynamic techniques and considerations regarding their application. Man Ther 12: 213-221. 